\title{
Research Square \\ Community-Based Survey On Reported Increased Mortality In Kano State
}

Yusuf Yau Gambo ( $\nabla$ yygambo@gmail.com )

\section{Short Report}

Keywords: Mortality, COVID-19, community

Posted Date: July 30th, 2020

DOI: https://doi.org/10.21203/rs.3.rs-49250/v1

License: (c) (1) This work is licensed under a Creative Commons Attribution 4.0 International License. Read Full License 


\title{
COMMUNITY-BASED SURVEY ON REPORTED INCREASED MORTALITY IN KANO STATE
}

\author{
Yusuf Ya'u Gambo \\ Department of Mathematics, Yusuf Maitama Sule University, Kano, Nigeria \\ yygambo@gmail.com, +234810404 4144
}

\begin{abstract}
Objectives: The main objectives of the study were to use data to corroborate the reported mysterious deaths being recorded in Kano state of Nigeria and find possible explanations to the causes.
\end{abstract}

Study design: This was a cross-sectional study.

Methods: With total lockdown in force at the time of conducting the survey, it was not possible to get data through one-on-one interview. Instead, an online survey form was developed and shared widely among residents in the state. The form captured quantitative data about symptoms and circumstances for the deceased and the respondents were only the state residents that witnessed the death cases in their respective communities.

Results: A total of 260 responses from various local government areas (LGAs) were received within a period of four days beginning from April 21, 2020. About half of the respondents affirmed that the death toll in their communities within the last two weeks before the survey were in multiples and most of the deaths started to occur from April 13 2020. Moreover, since then, the rate of deaths reported did not decline during the period of the research.

Conclusion: There was a sudden increase in the number of deaths due to acute illness suggestive of a disease. Highest number of deaths was recorded among senior adults, affecting males than females. The most affected area was Kano Municipal which was one of the populous LGA in the state. Although it was hard to point out the possible cause of death based on the data, however, the possibility of linking the situation to the current COVID-19 pandemic could not be ruled out. This was because the data strongly aligned with the pandemic in terms of symptoms, incubation period, age group affected and other demographic characteristics.

Keywords: Mortality, COVID-19, community 
Reportedly, there was high death toll in Kano State (the most populous city in Nigeria [1]) and there have been a lot of clamors for a robust investigation and communication by authorities concerned to allay the concerns of the residents in the state [2-3]. The investigation and explanation were extremely important especially in this period of a global pandemic and for the fact that large number of people in the state were in denial of the existence of the highly infectious and relentless SARS-CoV-2 virus. For instance, after the first initial reports of the reported deaths, Daily Trust reported that the Kano State Government denied the mysterious deaths being recorded within the state which created a lot of confusions and fears in the minds of people that witnessed the unprecedented deaths [4]. These concerns was reportedly intensified with the multiple deaths of prominent personalities in the state including six highly regarded professors. This also led to experts and residents calling on the state to urgently investigate and address the causes of the problem. Few days later, the Kano State Government acknowledged the recent deaths in the state [5].

As there was no formal investigation being carried out as at the time of this cross-sectional study conducted between April and May 2020, then a better way to improve the discussions was to present data that can clearly proves the occurrence of the strange deaths in the state. This notion motivated me to conduct this study to find some possible explanations to this mystery using quantitative data. One way to get the data was from the bereaved families directly or from residents that were close to these families in various communities. However, there was a total lockdown in the state that would make it difficult to acquire data through one to one interview. Instead, an online survey questionnaire was developed and shared widely among residents in the state. The questionnaire contained essential information about symptoms displayed by the deceased and the circumstances of deaths. The respondents were only Kano residents that witnessed the death cases in their communities. A total of 260 responses from various LGAs were received within a period of four days between April 21 to 242020 . Although the study was approved by an ethics committee of the study institution, nonetheless, no personal information of deceased and personal or contact information of respondents were captured.

It is important to address the limitations of the study. The main objective of the research is not to get the exact death toll in the state, but rather to generate aggregate data that can allow us to have an idea of what is going on. The study is not aiming at getting the current mortality rate in the state either. In fact, that might not be possible without an existing baseline data which was not available. However, the findings on this report could be useful to authorities concerned to take decisive actions.

Microsoft Power BI (March 2020 Update) was used for the analysis and visualizations. Descriptive statistics such as frequencies and percentages were used to present the findings.

In this study, $50 \%$ of the respondents asserted that the death toll in their communities within the last two weeks was higher than 5 and most of the deaths started occurring from April 132020 
which was about six weeks after recording the first case of COVID-19 in Nigeria [6]. Moreover, since then, the rate of deaths reported did not decline during the period of the research. From the data, it was impossible to ascertain the exact number of deceased that were hospitalized or visited hospitals as more than half of the respondents were oblivious. However, $22 \%$ of the respondents testified that the deceased were not hospitalized or did not visit any hospital. The results also indicated that the deceased were briefly ill- as brief as 1-10 days.

Most of the reported death cases by respondents happened in Kano metropolis with vast majority of deaths occurring in Kano Municipal LGA (21.6\%) which was one of the most populous LGA in the state. It is remarkable to note that all the LGAs in the metropolitan recorded this mass deaths but only few in the outskirt of Kano were affected.

The data strongly showed that more males died (91\%) than females and this was distributed across age group (Figure 1). On the other hand, it was obvious that elderly people were the ones mostly dying. The study also found out that fever was the last most prevailing symptom (41.3\%) experienced by the deceased (Figure 2).

In summary, while this report alone might not confirm the possible cause of the mysterious deaths happening in Kano state, however, it indicated that there was a genuine cause of concern as the increase in mortality seemed to be true and not only that, the possibility of linking the situation to COVID-19 could not be ruled out. The only way to confirm this would be by conducting autopsies on an adequate sample size.

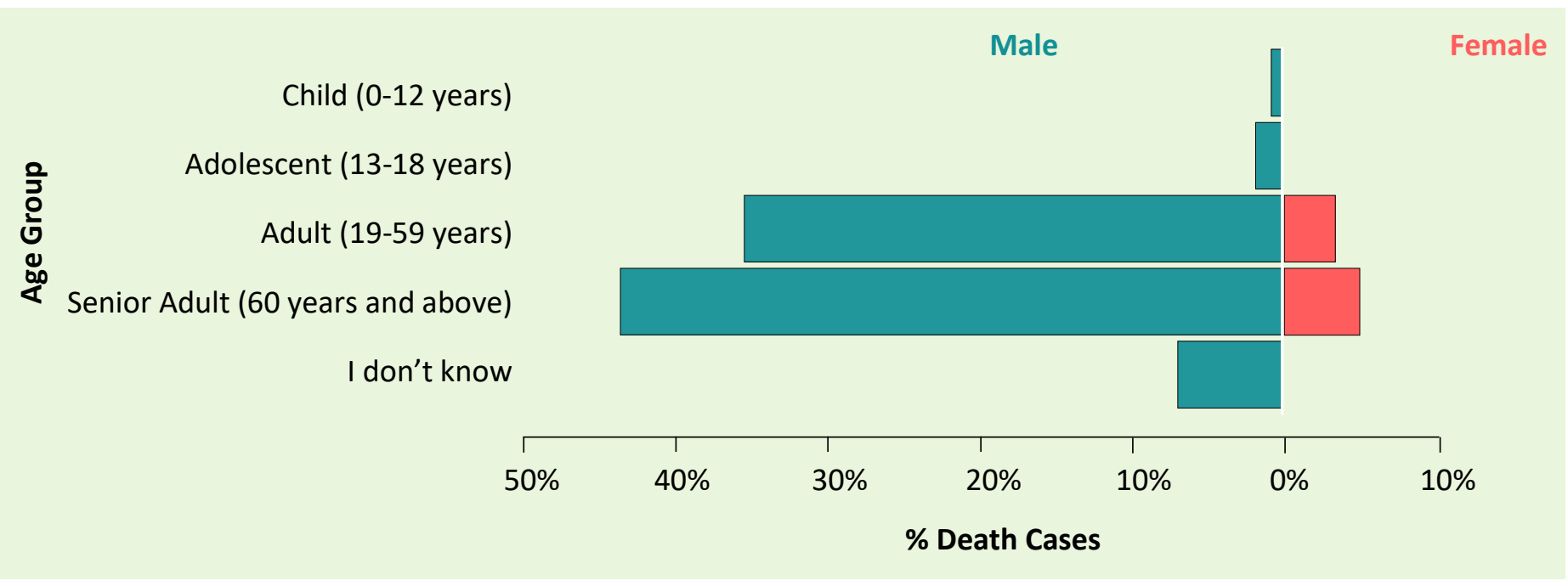

Fig. 1: Gender and age group of the deceased. 


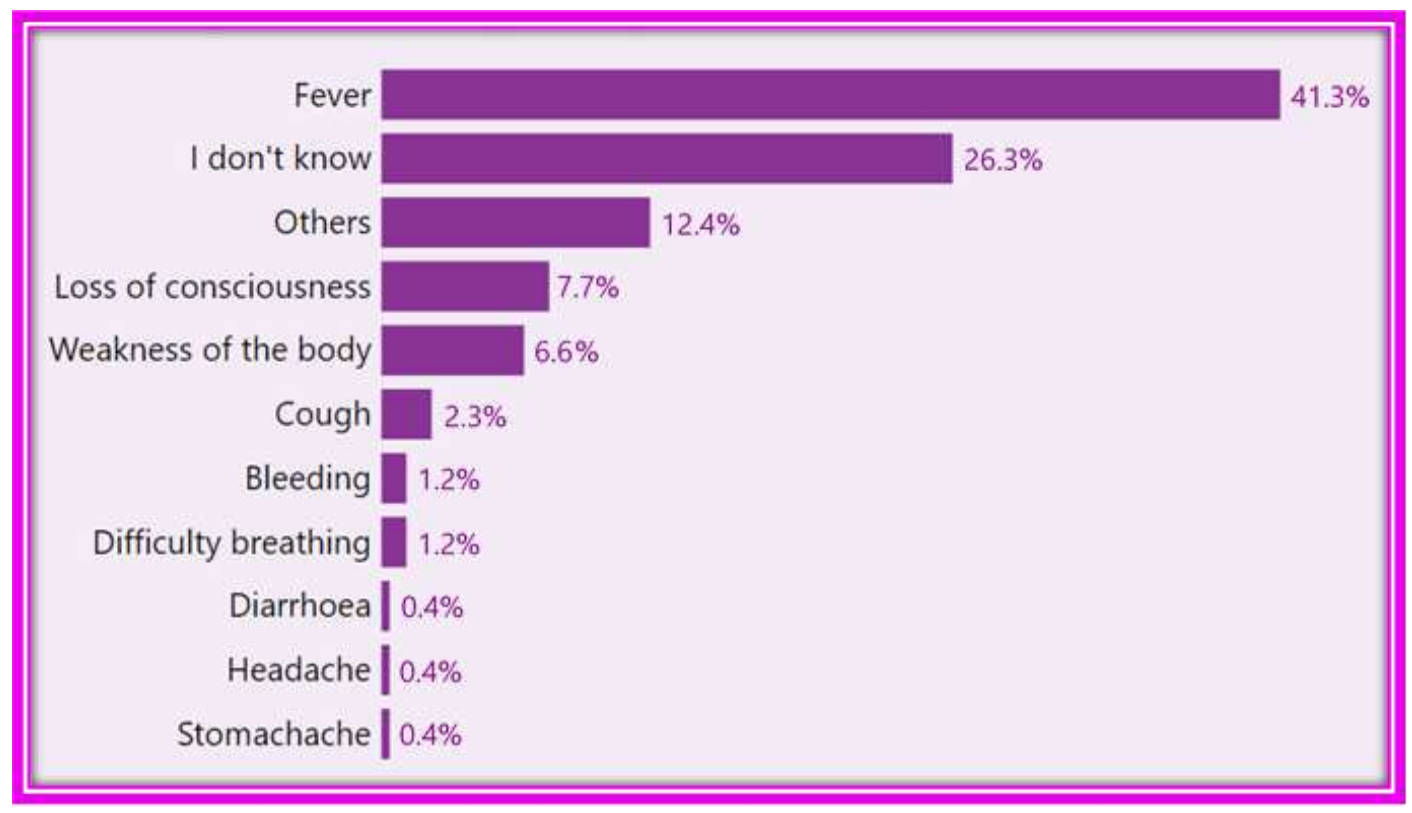

Fig. 2: Last known symptoms shown by the deceased.

\section{DECLARATIONS}

Ethics approval and consent to participate

The study was approved by an ethics committee of the study institution. The mode of data collection is online and the respondents participated of their own volition. No personal information of deceased and personal or contact information of respondents were captured.

\section{Consent for publication}

Not applicable

Availability of data and material

The datasets during and/or analysed during the current study available from the corresponding author on reasonable request.

\section{Competing interests}

The authors declare that they have no competing interests.

\section{Funding}

The research did not get any funding.

Authors' contributions

All contributions are made by the single author. 


\section{Acknowledgements}

I wish to thank Dr. Auwal Abubakar (MBBS, MPH, MSc) of Bauchi State Ministry of Health for his helpful clinical insights during the study.

\section{REFERENCES}

[1] National Bureau of Statistics. National Population Estimates, 2006-2016. Retrieved from: https://nigerianstat.gov.ng/elibrary?queries[search]=population

[2] The Gurdian. Deaths in Nigerian city raise concerns over undetected Covid-19 outbreaks, 2020. Retrieved from:

https://www.theguardian.com/world/2020/apr/28/nigerian-authorities-deny-wave-ofdeaths-is-due-to-covid-19 [Accessed 28 April, 2020].

[3] BBC. What is behind Nigeria's unexplained deaths in Kano?2020. Retrieved from: https://www.bbc.com/news/world-africa-52454259 [Accessed 28 April, 2020].

[4] Daily Trust. Funeral prayers for multiples as Kano death toll mounts, 2020. Retrieved from: https://www.dailytrust.com.ng/funeral-prayers-for-multiples-as-kano-death-tollmounts.html [Accessed 25 April, 2020].

[5] Kano State Government. Mysterious deaths in Kano: Govt. reacts, says unconnected with covid-19, 2020. Retrieved from:

https://www.kanostate.gov.ng/?q=mysterious-deaths-kano-govt-reacts-saysunconnected-covid-19 [Accessed 26 April, 2020].

[6] Nigeria Centre for Disease Control. COVID-19 Outbreak in Nigeria Situation Report, S/N: 001, 2020. Retrieved from:

https://ncdc.gov.ng/diseases/sitreps/?cat=14\&name=An\%20update\%20of\%20COVID19\%20outbreak\%20in\%20Nigeria [Accessed 20 April, 2020]. 
Figures

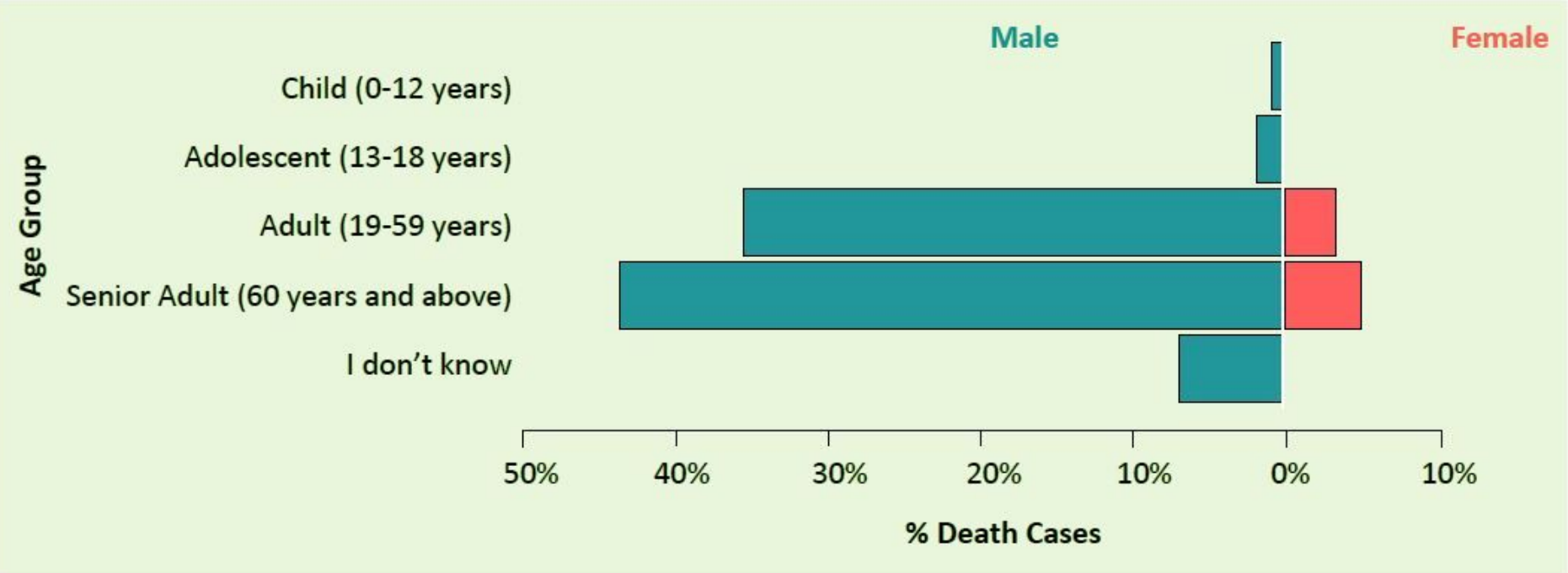

\section{Figure 1}

Gender and age group of the deceased.

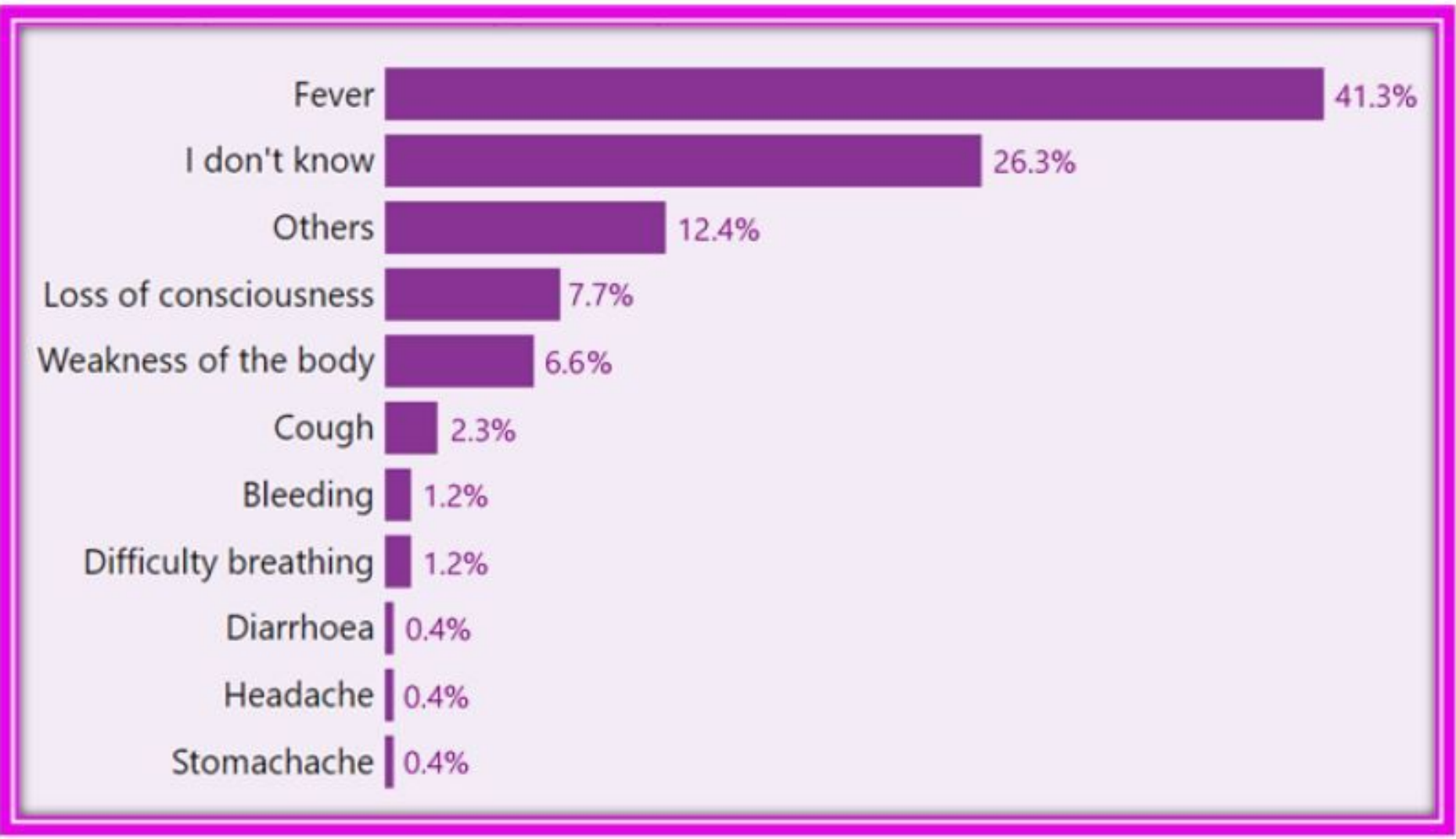

Figure 2

Last known symptoms shown by the deceased. 